\title{
MULTIPLE BREAST LUMPS: A RARE PRESENTATION OF ACUTE LYMPHOBLASTIC LEUKAEMIA
}

\author{
*SIDDIQUI MR ${ }^{1}$, ISLAM QT²
}

\begin{abstract}
:
Breast metastases in cases of leukemia are very rare and occur mostly in patients with acute myeloid leukemia (AML). We report a case of a young female who presented with bilateral breast lumps as the initial manifestation of acute lymphoblastic leukemia (ALL). On fine needle aspiration cytology, it was diagnosed as lymphoid malignancy, later confirmed as ALL using hematological investigations.
\end{abstract}

Key words: Breast Lump, Acute lymphoblastic leukemia, Pleural effusion.

\section{Introduction:}

Acute lymphoblastic leukemia (ALL) is a form of leukemia, or cancer of the white blood cells characterized by excess production of lymphoid precursor cells (ie, lymphoblasts). Malignant, immature lymphoblasts continuously multiply and replace the normal marrow elements, resulting in a marked decrease in the production of normal blood cells. ${ }^{1}$ ALL causes damage and death by crowding out normal cells in the bone marrow, and by spreading (infiltrating) to other organs. ALL is most common in childhood with a peak incidence at 2-5 years of age, and another peak in old age. The overall cure rate in children is about $80 \%$, and about $45 \%-60 \%$ of adults have long-term disease-free survival. ${ }^{1}$ ALL being fatal as little as a few weeks if left untreated.

Secondary malignancy to the breast from extramammary malignant neoplasms is unusual. ${ }^{2}$ Breast metastases in cases of leukemia are very rare and occur mostly in patients with acute myeloid leukemia (AML). Acute lymphoblastic leukemia (ALL) involving the breast is very uncommon. ${ }^{2,3}$ We report a case of a young female who presented with bilateral breast lumps as the initial manifestation of acute lymphoblastic leukemia. On fine needle aspiration cytology, it was diagnosed as lymphoid malignancy, later confirmed as ALL using hematological investigations.

\section{Case Report:}

A 18-year-old girl presented to us with painful swelling of the both breasts for 15 days, fever with progressive respiratory distress for last 7 days. Her past medical history was unremarkable. Clinical examination revealed that she had fever, generalized lymphadenopathy, bony tenderness and left sided pleural effusion. Local examination of the breast revealed multiple tender masses in the both breasts. All other systemic examinations were unremarkable.

Laboratory investigations revealed haemoglobin $(\mathrm{Hb})$ $-15.3 \mathrm{~g} / \mathrm{dL}$, Total white blood cell (WBC) count $67 \times 10^{9} / \mathrm{L}$, neutrophil- $12 \%$, lymphocyte- $10 \%$, monocyte- $1 \%$, blast cell- $75 \%$, Total platelet count$80 \times 10^{9} / \mathrm{L}$, peripheral blood film (PBF)- WBC showed shift to the left with majority cell blast with thrombocytopenia, erythrocyte sedimentation rate (ESR)- $10 \mathrm{~mm}$ in $1^{\text {st }}$ hour. Pleural fluid R/E showed numerous red blood cell (RBC), total leucocyte count$25,500 \mathrm{c} / \mathrm{mm}^{3}$, neutrophil- 03\%, lymphocyte- $72 \%$ and atypical mononeuclear cell- $25 \%$, protein- 5.30 $\mathrm{g} / \mathrm{dL}$, sugar- $48 \mathrm{mg} / \mathrm{dL}$. An ultrasonographic (USG) evaluation of the both breasts showed sonographycally hypoechoic and irregular masses having defined

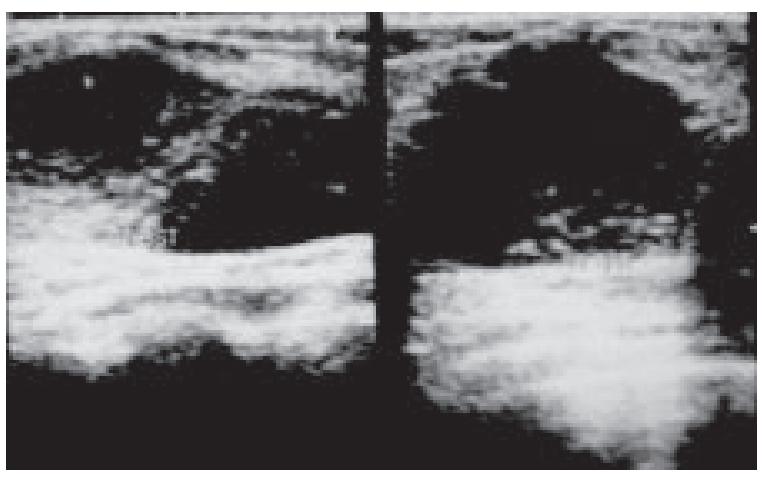

Fig 1: USG showing multiple inflammatory masses in the both breasts.

1. Assistant Professor, Department of Medicine, Anwer Khan Modern Medical College, Dhaka.

2. Professor, Department of Medicine, Popular Medical College, Dhaka. 


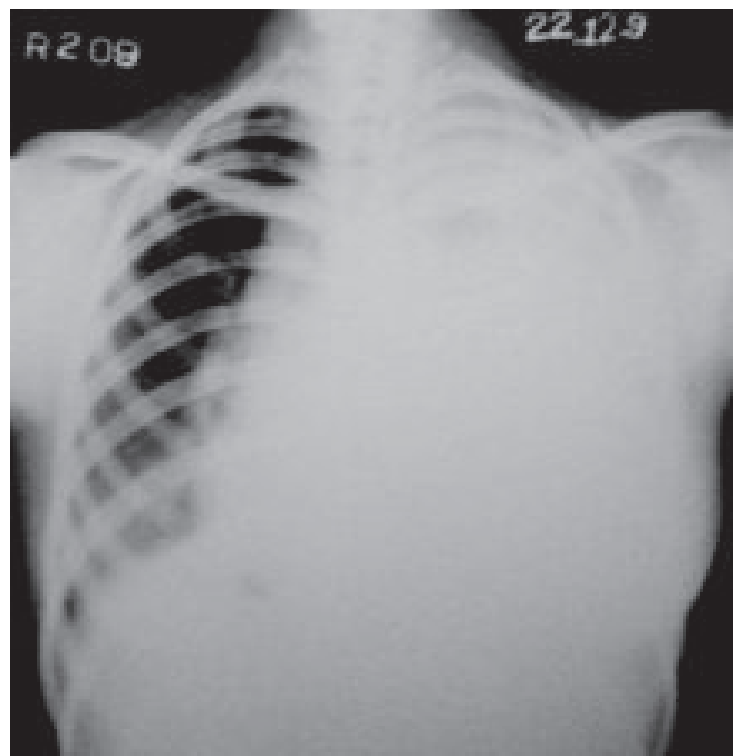

Fig 2: $X$-ray chest $P / A$ view showing massive pleural effusion in the left side.

capsule. The masses give honeycomb like appearance. USG guided Fine needle aspiration cytology (FNAC) of the breast masses revealed numerous blast cells. USG of the abdomen showed enlarged para-aortic, peri-pancreatic, porta-hepatic lymphnodes, left sided massive \& right sided mild pleural effusion with pericardial effusion. Bone marrow study showed features of Acute Lymphoblastic Leukaemia (ALL).

\section{Discussion:}

Secondary malignancy to the breast from extramammary malignant neoplasms is unusual and was described first in $1903 .^{2}$ Lymphoma, malignant melanoma, rhabdomyosarcoma are most common tumors metastasize to the breast. ${ }^{2}$ Breast metastases may be the initial manifestation of malignant disease. Metastases are frequently multiple and bilateral. ${ }^{4}$ They clinically manifest as well marginated, mobile, rapidly enlarging masses. ${ }^{5}$ Metastatic breast leukemia is very rare and occurs mostly in patients with acute myeloid leukemia. Metastatic acute lymphoblastic leukemia (ALL) to the breast is very uncommon. ${ }^{3}$

An ultrasonography is useful in young patients who usually have dense breasts tissue. ${ }^{6}$ However, in patients with extreme breast oedema, a mammography might not be useful to detect breast masses. Hence, in such cases, the ultrasonography would be performed. ${ }^{3,6}$ Sonographic features of breast metastases range widely, from hypoechoic to hyperechoic lesions. ${ }^{6,7}$ The involvement of the breasts in cases of acute leukemia has been described as multiple nodular areas of mixed echogenicity, with or without acoustic shadowing. ${ }^{8}$

Any enlarging breast mass, even one with an apparent benign sonographic appearance must be investigated promptly with fine-needle aspiration cytology or core needle biopsy. ${ }^{4,9}$ Medical imaging (such as X-ray, ultrasound, CT scanning and MRI) can find invasion of other organs commonly the lung, liver, spleen, lymph nodes, brain, kidneys, and reproductive organs. ${ }^{5}$ In our case, there was also invasion of the pleural space which presented as left sided massive pleural effusion and numerous blast cells also revealed from pleural fluid.

\section{Conflict of interest:}

We have no conflict of interest.

\section{Acknowledgement:}

We are grateful to the patient and her guardian for their consent.

\section{Author's contribution:}

Dr. Mahmudur Rahman Siddiqui: involve in writing the article, collect all the documents \& pictures and treating the patient. Prof. Quazi Tarikul Islam: involve in review the article and treating consultant of the patient.

\section{Reference:}

1. Longo DL. Malignancies of Lymphoid Cells. Clinical Features, Treatment, and Prognosis of Specific Lymphoid Malignancies. In Fauci AS et al (ed) Harrison's Principles of Internal Medicine, 17th Edition, USA, The McGraw-Hill Companies, 2008; 105: 687-700.

2. Basara I, Orguc S. Giant Breast Involvement in Acute Lymphoblastic Leukemia: MRI Findings. J Breast Cancer 2012; 15(2): 258-60.

3. Bayrak IK, Yalin T, Ozmen Z, et al. Acute Lymphoblastic Leukemia Presented as Multiple Breast Masses. Korean J Radiol 2009; 10: 508-10.

4. Hays DM, Donaldson SS, Shimada H, et al. Primary and metastatic rhabdomyosarcoma in the breast: neoplasms of adolescent females, a report from the Intergroup Rhabdomyosarcoma Study. Med Pediatr Oncol 1997; 29: 181-9.

5. Cunningham I. A clinical review of breast involvement in acute leukemia. Leuk Lymphoma 2006; 47: 2517-26.

6. Likaki-Karatza E, Mpadra FA, Karamouzis MV, et al. Acute lymphoblastic leukemia relapse in the breast diagnosed with gray-scale and color Doppler sonography. J Clin Ultrasound 2002; 30: 552-56.

7. Yang WT, Muttarak M, Ho LW. Nonmammary malignancies of the breast: ultrasound, CT, and MRI. Semin Ultrasound CT MR 2000; 21:375-94.

8. Guermazi A, Quoc SN, Socie G, et al. Myeloblastoma (chloroma) in leukemia: case Granulocytic sarcoma (chloroma) of the breast. J Clin Oncol 2001; 18: 3993-96.

9. West KW, Rescorla FJ, Scherer LR, et al. Diagnosis and treatment of symptomatic breast masses in the pediatric population. J Pediatr Surg 1995; 30:182-6. 